\title{
Application of random walk to model temperature in 60 African cities for the $20^{\text {th }}$ century
}

\author{
Shaomin $\mathrm{Yan}^{1}$, and Guang $\mathrm{Wu}^{* 1}$ \\ ${ }^{1}$ National Engineering Research Center for Non-Food Biorefinery, State Key Laboratory of Non-Food Biomass and Enzyme Technology, \\ Guangxi Biomass Engineering Technology Research Center, Guangxi Key Laboratory of Biorefinery, Guangxi Academy of Sciences, 98 \\ Daling Road, Nanning, 530007, Guangxi, China
}

\begin{abstract}
The $20^{\text {th }}$ century is marked with climate change led by global warming. So far, many models have been applied to analyze the temperature change. However, a simple but interesting model, a random walk is hardly used in his regard. In this study, we use the random walk to model the temperature in the format of random walk that is the conversion of recorded temperature and the real recorded temperature in 60 African cities including 53 capitals for the $20^{\text {th }}$ century. The results show that the random walk can satisfyingly model either temperature in the format of random walk or real recorded temperature although the fitted results from other climate models are unavailable for comparison in these 60 cities. As nothing else besides random numbers is involved in this modelling, the results seem somewhat counter-intuitively.
\end{abstract}

\section{Introduction}

The climate change is a topic too important to use just a few models to reach a solid conclusion, thus every effort should be made to use all the possible models to address this issue carefully and throughout until we exhaust all our already-known models. Highly likely, we have not yet exhausted all our already-known models to analyze and explain the temperature changes.

Although random walk model was proposed to deal with the global warming in the $90 \mathrm{~s}$ in the $20^{\text {th }}$ century [1], the real application of random walk model was impeded by the lack of computation power.

In the $20^{\text {th }}$ century, the computation power is no longer the limiting factor for such work, so we have the opportunity to use the random walk to model the real temperature.

The currently very complicated climate models seem to fall behind the public expectation that public can verify the temperature change using models because the social network, advocated-democracy and Wiki phenomenon give strong impulses to public to verify what they are told by either scientists or politicians. In this context, one cannot verify the theory of global warming without supercomputer and related expertise. Therefore, it is important and pressing to apply some simple model to treat the temperature changes.

In this context, we apply the random walk to model the temperature in 60 African cities including 53 capitals for the $20^{\text {th }}$ century in this study. In the random walk model, the random factors will no longer be considered as minor players as in other models [2], but as the only mechanism for temperature change.

\section{Materials and methods}

\subsection{Data}

Sixty cities of Africa are chosen according to Wikipedia [3], which are listed in Table 2 . Based on $0.5^{\circ}$ by $0.5^{\circ}$ latitude and longitude grid-box basis cross globe, the temperatures in these 60 African cities recorded for the 20th century are obtained from the website of Oak Ridge National Laboratory [4]. The latitudes and longitudes of these 60 cities are determined using Find Latitude and Longitude [5].

\subsection{Temperature in the format of random walk}

Although temperature recorded along the time course is decimal number, it can be simplified as higher or lower or equal to that in previous recording, which results in 1 , -1 and 0 in numerical term. The addition of \pm 1 along the time course is the one-dimensional random walk starting from zero [6]. In plain words, the random walk can be viewed as a sequential result of tossing a fair coin, by which we record the head as 1 and the tail as -1 , and then we add the results together along the time course.

For this purpose, we convert the temperature into a format similar to random walk as shown in Table 1. For example, the average temperature in 1901 was $15.825 \mathrm{C}$ (cell 2, column 2, Table 1), the temperature in 1902 is higher than that in 1901 (16.275 C vs. $15.825 \mathrm{C})$, so we assign 1 (cell 3, column 3, Table 1). Then, the temperature in 1903 is lower than that in 1902 (15.675 C

\footnotetext{
* Corresponding author: hongguanglishibahao@gxas.cn
} 
vs. 16.275 C), so we assign -1 (cell 4, column 3, Table

$1)$, and then we add them together to construct

temperature walk (column 4, Table 1)

Table 1. Procedure of converting the temperature in Algiers for the $20^{\text {th }}$ century into its format of random walk and generation of random walk.

\begin{tabular}{|c|c|c|c|c|c|c|}
\hline Year & $\begin{array}{c}\text { Temperature } \\
\mathrm{C}\end{array}$ & $\begin{array}{c}\text { Converted } \\
\text { Temperature }\end{array}$ & $\begin{array}{l}\text { Temperature } \\
\text { Walk }\end{array}$ & $\begin{array}{c}\text { Generated Random } \\
\text { Number }\end{array}$ & $\begin{array}{l}\text { Random Walk } \\
\text { Step }\end{array}$ & $\begin{array}{l}\text { Random } \\
\text { Walk }\end{array}$ \\
\hline 1901 & 15.825 & & 0 & -0.47192 & & 0 \\
\hline 1902 & 16.275 & 1 & 1 & -0.88720 & -1 & -1 \\
\hline 1903 & 15.675 & -1 & 0 & 0.57078 & 1 & 0 \\
\hline 1904 & 16.108 & 1 & 1 & 0.20363 & -1 & -1 \\
\hline 1905 & 15.667 & -1 & 0 & -0.46987 & -1 & -2 \\
\hline 1906 & 15.433 & -1 & -1 & -0.36344 & 1 & -1 \\
\hline 1907 & 15.417 & -1 & -2 & 0.64925 & 1 & 0 \\
\hline 1908 & 16.033 & 1 & -1 & 0.09431 & -1 & -1 \\
\hline 1909 & 15.075 & -1 & -2 & 0.86238 & 1 & 0 \\
\hline 1910 & 15.175 & 1 & -1 & 0.42282 & -1 & -1 \\
\hline$\ldots$ & $\ldots$ & $\ldots$ & $\ldots$ & $\ldots$ & $\ldots$ & $\ldots$ \\
\hline 1989 & 18.892 & 1 & 4 & -0.21946 & -1 & 2 \\
\hline 1990 & 18.658 & -1 & 3 & 0.73550 & 1 & 3 \\
\hline 1991 & 17.567 & -1 & 2 & 0.55552 & -1 & 2 \\
\hline 1992 & 17.500 & -1 & 1 & -0.74005 & -1 & 1 \\
\hline 1993 & 17.642 & 1 & 2 & -0.30770 & 1 & 2 \\
\hline 1994 & 18.833 & 1 & 3 & -0.93889 & -1 & 1 \\
\hline 1995 & 18.475 & -1 & 2 & -0.36484 & 1 & 2 \\
\hline 1996 & 17.883 & -1 & 1 & 0.27173 & 1 & 3 \\
\hline 1997 & 18.642 & 1 & 2 & -0.41865 & -1 & 2 \\
\hline 1998 & 17.925 & -1 & 1 & 0.72083 & 1 & 3 \\
\hline
\end{tabular}

\subsection{Generation of random walk}

So far, difference methods have been used to generate the random numbers, for example, the Monte-Carlo methods in SigmaPlot [7]. The second part of Table 1 shows how to generate a random walk. A sequence of random numbers was generated using SigmaPlot (column 5, Table 1). The second random number is 0.8872 (cell 3, column 5, Table 1), which is smaller than the first random number (cell 2, column 5, Table 1), so we assign -1 (cell 3, column 6, Table 1). Following the similar procedure in the last section, we construct the random walk (the last column in Table 1).

\subsection{Searching for seed}

For any random number generator, the command usually as follows: seed, number of generated random numbers, up and low ranges. If a seed that can generate random numbers whose random walk is most similar to temperature walk, then this seed would be best. However, this is not an easy task, therefore we used a brutal force method to try each sequence of random numbers with 1 million seeds.

\subsection{Extension of random walk}

In reality, temperature is a decimal number rather than 1 , $0,-1$ as those in random walk. Similarly, the random number generator generates decimal numbers rather than $1,0,-1$. These provide the possibility to use a sequence of random numbers to construct a random walk, and use the recorded temperature to construct a temperature walk.

\subsection{Comparison}

The least squares method is used for comparison between the temperature in the format of random walk and random walk, and between temperature and decimal random walk.

\section{Results and discussion}

As the random mechanism is the only player in the random walk model, thus the use of random walk to model either temperature in the format of random walk or temperature is not difficult, and every one can in principle do this job easily and conveniently. This is in clear contrast to the current climate models, where random factors are generally considered as noises [2].

Figure 1 shows the application of random walk model to the temperature in the format of random walk (left panel) and the temperature (right panel) in 5 representative cities at different locations in Africa.

On the left panel of Figure 1, the temperature in the format of random walk can take several steps either up or down, which would be arguably the trend for underlined temperature trend as we have already seen the temperature increased over some years. Although the temperature in the format of random walk is the conversation from recorded temperature, it can indeed be modelled by a random walk whether it goes up or down. 
In fact, we would not expect a perfect fitting for 100 years because the chance is too small, $(1 / 2)^{100}$, to achieve as tossing a fair coin has $1 / 2$ probability to be head up or down. As these fittings were done in all 60 cities without any exception (columns 3 and 4 in Table 2), it would suggest that the temperature in the format of random walk could be attributed to a random mechanism.

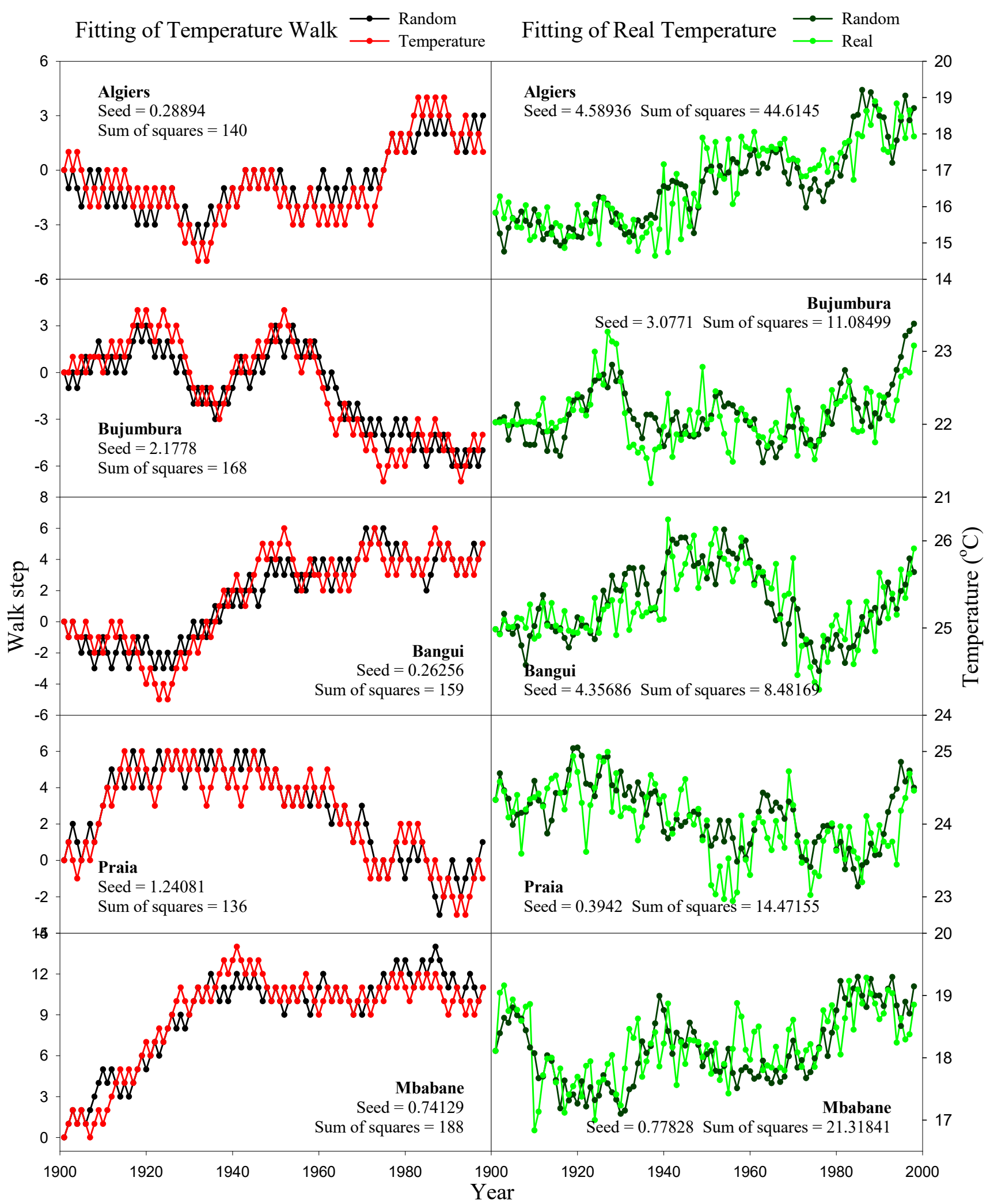

Fig. 1. Comparison between the temperature in the format of random walk an random walk (left panel) and between temperature and decimal random walk (right panel). 
Table 2. Seeds for generation of random numbers for modelling of temperature in the format of random walk (column 3 ) and recorded temperature (column 4 ).

\begin{tabular}{|c|c|c|c|}
\hline State/Island/City & Capital/Main City & Seeds & Seeds \\
\hline Algeria & Algiers & 0.28894 & 4.58936 \\
\hline Angola & Luanda & 0.06963 & 1.02646 \\
\hline Benin & Porto-Novo & 4.92860 & 0.45102 \\
\hline Botswana & Gaborone & 3.97033 & 2.24124 \\
\hline Burkina Faso & Ouagadougou & 1.67443 & 2.73101 \\
\hline Burundi & Bujumbura & 2.17780 & 3.07710 \\
\hline Cameroon & Yaoundé & 1.12887 & 0.84994 \\
\hline Canary Islands (Spain) & Las Palmas de Gran Canaria & 5.23634 & 2.23310 \\
\hline Cape Verde & Praia & 1.24081 & 0.39420 \\
\hline Central African Republic & Bangui & 0.26256 & 4.35686 \\
\hline Ceuta (Spain) & - & 5.81828 & 3.49371 \\
\hline Chad & N'Djamena & 1.06187 & 0.52598 \\
\hline Comoros & Moroni & 0.76109 & 0.01219 \\
\hline Côte d'Ivoire & Abidjan & 6.60339 & 7.34362 \\
\hline Democratic Republic of the Congo & Kinshasa & 5.33755 & 0.29761 \\
\hline Djibouti & Djibouti & 1.52317 & 3.94442 \\
\hline Egypt & Cairo & 8.52921 & 2.41488 \\
\hline Equatorial Guinea & Malabo & 2.32397 & 3.54964 \\
\hline Eritrea & Asmara & 1.21252 & 5.96245 \\
\hline Ethiopia & Addis Ababa & 1.78082 & 4.26952 \\
\hline Gabon & Libreville & 0.52118 & 3.84746 \\
\hline Ghana & Accra & 0.50938 & 4.52341 \\
\hline Guinea & Conakry & 0.48103 & 2.80122 \\
\hline Guinea-Bissau & Bissau & 0.45082 & 7.20704 \\
\hline Kenya & Nairobi & 1.38852 & 1.00904 \\
\hline Lesotho & Maseru & 2.02340 & 8.35252 \\
\hline Liberia & Monrovia & 1.29483 & 0.80564 \\
\hline Libya & Tripoli & 0.63052 & 0.07157 \\
\hline Madagascar & Antananarivo & 7.39082 & 3.79777 \\
\hline Madeira Islands (Portugal) & Funchal & 0.71346 & 0.53171 \\
\hline Malawi & Lilongwe & 3.31921 & 2.19555 \\
\hline Mali & Bamako & 3.58343 & 5.96289 \\
\hline Mauritania & Nouakchott & 0.95814 & 3.39094 \\
\hline Mauritius & Port Louis & 4.90808 & 0.01219 \\
\hline Mayotte (France) & Mamoudzou & 0.48937 & 4.26447 \\
\hline Melilla (Spain) & - & 2.06516 & 2.23310 \\
\hline Morocco & Rabat & 2.58505 & 0.98484 \\
\hline Mozambique & Maputo & 0.78381 & 0.52342 \\
\hline Namibia & Windhoek & 1.44089 & 0.00980 \\
\hline Niger & Niamey & 3.10076 & 0.26236 \\
\hline Nigeria & Abuja & 2.57323 & 1.63191 \\
\hline Republic of the Congo & Brazzaville & 5.33755 & 0.29761 \\
\hline Réunion (France) & Saint-Denis & 0.08955 & 1.04547 \\
\hline Rwanda & Kigali & 0.29356 & 2.61825 \\
\hline Santa Cruz de Tenerife & - & 0.16051 & 2.23310 \\
\hline São Tomé and Príncipe & São Tomé & 8.77678 & 3.84746 \\
\hline Senegal & Dakar & 1.39995 & 0.06963 \\
\hline Seychelles & Victoria & 1.39836 & 1.68698 \\
\hline Sierra Leone & Freetown & 0.88954 & 0.97418 \\
\hline Somalia & Mogadishu & 0.70028 & 0.43083 \\
\hline South Africa & Pretoria & 4.39973 & 1.53916 \\
\hline Sudan & Khartoum & 6.17171 & 2.13654 \\
\hline Swaziland & Mbabane & 0.74129 & 0.77828 \\
\hline Tanzania & Dodoma & 2.04458 & 1.30204 \\
\hline The Gambia & Banjul & 2.37399 & 2.10617 \\
\hline Togo & Lomé & 0.69901 & 0.43821 \\
\hline Tunisia & Tunis & 7.96571 & 3.99012 \\
\hline Uganda & Kampala & 2.55225 & 2.51977 \\
\hline Zambia & Lusaka & 0.71026 & 1.46179 \\
\hline Zimbabwe & Harare & 1.27065 & 3.88437 \\
\hline
\end{tabular}


On the right panel of Figure 1, we used the random walk model to fit the real recorded temperature. As can be seen, the fittings by random walk go along the general trend of recorded temperature. The fitted results are listed in columns 5 and 6 in Table 2.

Unfortunately, we have not the results in these 60 cities using other climate models for comparison, however, our results can be considered satisfying because the fluctuated fitting curve cannot be produced by any deterministic model operating on differential equations.

If the temperature in the format of random walk is a deliberate and artificial conversation from the recorded temperature, then the fittings in the right panel of Figure 1 can exclude such a possibility. This not only simply means that the random walk model can fit the real recorded temperature, but also decisively means that the random mechanism can be considered as the driving force for the temperature change. If so, it is very natural that the temperature can continue to increase or decrease for sequential years before a turning point.

Also, the random walk model is very simple, which may dramatically reduce the uncertainty in comparison with the current climate models [8].

Although the $20^{\text {th }}$ century is marked with climate change led by global warming, African continent should be an exemption because Africa did not experience the industrial revolution, which polluted Europe. Thereafter, the rise of Japan, China, South Korea as well as East Asian countries increased the carbon emission in Asia. On the other hand, Africa could suffer the climate change severely, especially for sub-Saharan, where droughts occur frequently.

Table 2 shows the seeds used to generate random numbers for random walk modelling. As can be seen in Table 2, no repetition in seeds can be found, thus the temperature in each city has its own profile with a different seed.

Because there is no prior knowledge on the best seed, we have to search it from one million seeds from 0 to 1 although the real best seed might well be off this range. However, a compromise should be made in order to balance the computational time with the time required to finish a study.

As seen in Table 2, the seeds are usually smaller than 5 , which could provide a safeguard to our searching range from 0 to 1 .

As a matter of fact, this study finished our endeavour to use the random walk model to fit/simulate the temperature in different parts of the world [9-15]. The results seem to be similar across different continents.

\section{Conclusion}

Although the $20^{\text {th }}$ century is marked with climate change led by global warming, the $21^{\text {st }}$ century should be marked with its consequence and resolution. This study demonstrates the possibility to model the temperature changes using random walk, which could suggest a simpler mechanism.

\section{Acknowledgments}

This study was supported by Scientific Development Fund of Guangxi Academy of Sciences (2021YFJ1203).

\section{References}

1. A. H. Gordon, J. Clim., 4, 589-597 (1991).

2. P. D. Williams, Phil. Trans. R. Soc. A 363, 29312946 (2005)

3. Wikimedia Foundation, Inc. Wikipedia, the free encyclopedia,

http://en.wikipedia.org/wiki/Countries of Africa. (2020)

4. M. New, M. Hulme, P. Jones, J. Clim. 13, $2217-$ $2238(2000)$

5. https://www.findlatitudeandlongitude.com/. (2020)

6. Wikimedia Foundation, Inc. Wikipedia, the free encyclopedia, http://en.wikipedia.org/wiki/Random_walk (2020)

7. SPSS Inc. SigmaPlot 2002 for Windows Version 8.02, (1986-2001)

8. G.C. Cawley, G.J. Janacek, M.R. Haylock, S.R. Dorling, Neural Netw. 20, 537-549 ( 2007)

9. S. Yan, G. Wu, Guangxi Sci. 17, 148-150 (2010)

10. S. Yan, G. Wu, Natural Sci. 2, 1425-1431 (2010).

11. S. Yan, G. Wu, Guangxi Sci. 20, 115-120 (2013)

12. S. Yan, G. Wu, New Developments in Global Warming Research. ed. C.B. Keyes, O.C. Lucero, Nova Science Pub Inc., New York, Chapter 7, 143156 (2013)

13. S. Yan, G. Wu, 2020 IEEE 3rd International Conference on Automation, Electronics and Electrical Engineering (AUTEEE 2020), AE345:. IEEE Xplore. 121-124

14. S. Yan, G. Wu, Proceedings of the 3rd International Forum on Geoscience and Geodesy (IFGG 2020) IOP Conference Series: Earth and Environmental Science (IOP Conf. Ser.: Earth Environ. Sci). 658: 012037 (2021)

15. S. Yan, G. Wu, Proceedings of the 3nd International Conference on Environmental Prevention and Pollution Control Technologies (EPPCT 2021) IOP Conference Series: Earth and Environmental Science (in press) 